\title{
On the Scattering of the Sun's Ray in the High Atmosphere (III)
}

\author{
By T. Sato \\ Nagasaki University \\ (Manuscript received 18 August 1966, in revised form 6 June 1967)
}

\begin{abstract}
The flux of primary scattered radiation received by the horizontal plane of $1 \mathrm{~cm}^{2}$ at 75 levels placed at intervals of $500 \mathrm{~m}$ from $1 \mathrm{~km}$ to $38 \mathrm{~km}$ are computed for solar altitudes $30^{\circ}$, $60^{\circ}$ and $90^{\circ}$ and the results summarized in the following four points are obtained;

(1) The flux decreases with increase of $q$ for given $h$ and $\lambda_{i}{ }^{\prime}$

(2) the flux increases with increase of $h$ for given $q$ and $\lambda_{i}{ }^{\prime}$

(3) the wavelength in which the flux is maximum decreases with increase of $q$ for given $h$

(4) the wavelength mentioned in (3) decreases with increases of $h$ for each $q$
\end{abstract}

\section{Introduction}

As the altitude becomes higher and higher in the atmosphere, the blue sky becomes darker and darker. The problem of Rayleigh scattering of light, which has an essential relation to this fact, has not yet been fully solved in spite of its major importance in all problems relating to the radiational effects in the atmosphere.

The author has studied the problems related to this in a paper (Sato, 1962) and in a series of papers titled: On the Scattering of the Sun's Ray in the High Atmosphere.

In the first paper of this study (Sato, 1955) the author computed the intensity of scattered light at $5 \mathrm{~km}$ level in four wavelength ranges, each of which has the energy equal to $x / 4$ of the total solar energy at the upper boundary of the earth's atmosphere. In the second paper (Sato, 1964) he did the same computation for 75 levels placed at intervals of $500 \mathrm{~m}$ from $1 \mathrm{~km}$ to $38 \mathrm{~km}$. Moreover the total solar energy is divided into 12 wavelength ranges, each of which has the energy equal to $1 / 12$ of the total energy. The study is restricted only to the primary scattered light in the vertical plane normal to the vertical plane passing through the center of the sun in the sky dome. In this (third) paper, he computed the flux of primary scat- tered radiation received by the horizontal plane of $1 \mathrm{~cm}^{2}$ at the above mentioned 75 levels for solar altitudes $30^{\circ}, 60^{\circ}$ and $90^{\circ}$ and obtained the results summarized in four points given in Section 6 .

\section{The method of computation}

Let 0 and $0^{\prime}$ be the earth's centre and a point on its surface. Take 75 points $E_{1} E_{2} \cdots$ $\cdots E_{q} \cdots \cdots E_{75}$ on the prolonged line of $00^{\prime}$, i.e. the vertical line at $0^{\prime}$. The elevation of $E_{1}$ is $1 \mathrm{~km}$, and two adjacent points $E_{q}$ and $E_{q+1}$ are apart from each other by $500 \mathrm{~m}$. Hence, $O^{\prime} E_{q}=1 / 2(q+1) \mathrm{km}$. Consider a horizontal plane of $1 \mathrm{~cm}^{2}$ area on $E_{q}$ point, which is vertical to $O E_{q}$. It is named $E_{q}$ plane. This plane can receive the primary scattered radiation generated by the atmosphere in the sky dome bounded by a horizontal plane at $E_{q}$ and the atmospheric upper limit. In the following we compute the flux of primary scattered radiation received by the upper side of $E_{q}$ plane. Now we divide the total energy of the Sun outside the earth's atmosphere into twelve domains. Let $p_{i}, \lambda_{i}, \lambda_{i}{ }^{\prime}, k_{i}$ and $I_{0}\left(\lambda_{i}{ }^{\prime}\right)$ be respectively the mean transmission coefficient of each domain, the upper limit of wavelength of the domain, the wavelength corresponding to $p_{i}$, extinction coefficient corresponding to $p_{i}$ and the Sun's energy out- 
Table 1. The values of $p_{i} \lambda_{i} \lambda_{i}{ }^{\prime} I_{0}\left(\lambda_{i}{ }^{\prime}\right) k_{i}$

\begin{tabular}{|c|c|c|c|c|c|c|}
\hline$i$ & 1 & 2 & 3 & 4 & 5 & 6 \\
\hline$p_{i}$ & 0.600 & 0.795 & 0.867 & 0.912 & 0.941 & 0.961 \\
\hline$\lambda_{i}$ & 0.409 & 0.466 & 0.519 & 0.577 & 0.638 & 0.708 \\
\hline$\lambda_{i}^{\prime}$ & 0.3572 & 0.4364 & 0.4910 & 0.5445 & 0.6088 & 0.6763 \\
\hline$I_{0}\left(\lambda_{i}{ }^{\prime}\right)$ & 1655 & 2806 & 3109 & 2799 & 2643 & 2321 \\
\hline$k_{i}$ & $0,4924 \cdot 10^{-3}$ & $0,2210 \cdot 10^{-3}$ & $0,1380 \cdot 10^{-3}$ & $0,8915 \cdot 10^{-4}$ & $0,5836 \cdot 10^{-4}$ & $0,3832 \cdot 10^{-4}$ \\
\hline$i$ & 7 & 8 & 9 & 10 & 11 & 12 \\
\hline$p_{i}$ & 0.973 & 0.985 & 0.991 & 0.995 & 0.998 & 1.000 \\
\hline$\lambda_{i}$ & 0.793 & 0.905 & 1. 058 & 1. 282 & 1. 738 & $\infty$ \\
\hline$\lambda_{i}^{\prime}$ & 0.7456 & 0.8567 & 0.9850 & 1. 1396 & 1. 4960 & 2.5356 \\
\hline$I_{0}\left(\lambda_{i}\right)^{\prime}$ & 1923 & 1405 & 1065 & 457 & 352 & 74 \\
\hline$k_{i}$ & $0,2595 \cdot 10^{-4}$ & $0,1482 \cdot 10^{-4}$ & $0,8519 \cdot 10^{-5}$ & $0,4753 \cdot 10^{-5}$ & $0,1601 \cdot 10^{-5}$ & $0,1940 \cdot 10^{-6}$ \\
\hline
\end{tabular}

side the earth's atmosphere. We have the following table (Sato, 1955). (Table 1).

$I_{0}\left(\lambda_{i}{ }^{\prime}\right)$ is obtained from Abbot's research and Linke's Table. The unit and wavelength width are $\left(\mathrm{cal} / \mathrm{cm}^{2} \cdot \mathrm{min}\right) \cdot 10^{-6}$ and $0.001 \mu$.

Let $\theta_{1}$ be the angle between a line passing through $E_{q}$ and $O E_{q}$ line, which is hereafter denoted by $\theta_{1}$ line. Let $A$ be the azimuth of the vertical plane containing $\theta_{1}$ line relative to the Sun's azimuth. Take the following values of $\theta_{1}$ and $A: \theta_{1}=95+5 n \quad(n=0 \sim 5), 150$, 180 in degree, $A=0, \pi / 2, \pi, 3 \pi / 2$.

In this case the atmospheric model is the same as in Part I (Sato, 1955) and its upper limit is $40 \mathrm{~km}$. Let $0^{\prime \prime}$ be the intersecting point of $\theta_{1}$ line by the atmospheric upper limit, and now let $T_{r}$ be a point on $\theta_{1}$ line which is apart from $E_{q}$ by the distance of $r$. The amount of primary scattered intensity $d p_{1}$ received at $E_{q}$ from a region of spherical shell of $1 \mathrm{~m}$ width with its center at $T_{r}$ bounded by a cone of one steradian with its axis in $\left(\theta_{1} A\right)$ direction and its vertex at $E_{q}$ is expressed in the unit of intensity of incident solar radiation as follows

$$
d p_{1}=\frac{3 k_{i} \rho\left(T_{r}\right)}{16 \pi}\left(1+\cos ^{2} \varphi\right) p_{i}{ }^{\Sigma(T r)}
$$

$$
\cos \varphi=\sin \theta_{1} \cos A \cos h-\cos \theta_{1} \operatorname{sih} h,
$$

where $h$ is the solar elevation, $\rho\left(T_{r}\right)$ the atmospheric mass in $1 \mathrm{~m}^{3}$ at $T_{r}$ and $\Sigma\left(T_{r}\right)$ is the sum of two traversed masses, one of which is the mass between the upper atmospheric limit and $T_{r}$ and the other is that between
$T_{r}$ and $E_{q}$ in the unit of whole atmospheric mass penetrated by the vertical cylinder at $0^{\prime}$ (Sato, 1964).

Now put

$$
\rho\left(T_{r}\right) p_{i}^{\Sigma\left(T_{r}\right)}=S^{\prime}\left(i q \theta_{1} A r h\right)
$$

then

$$
d p_{1}=\frac{3 k_{i}}{16 \pi}\left(1+\cos ^{2} \varphi\right) S^{\prime}\left(i q \theta_{1} A r h\right)
$$

Let us denote

$$
d H_{p s}=d P_{1} \sin \left(\theta_{1}-90^{\circ}\right)
$$

Then we have only to carry out multiple integration to $d H_{p s} \cos \left(\theta_{1}-90^{\circ}\right)$ with respect to $r$ from $E_{q}$ to $0^{\prime \prime}$ along $\theta_{1}$ line and $\theta_{1}$ from $\theta_{1}=\pi / 2$ to $\pi$ and $A$ from $A=0$ to $A=2 \pi$ to find the flux of primary scattered radiation received by the horizontal plane $H_{p s}(i q h)$ at $E_{q}$, i.e.

$H_{p s}(i q h)=\int_{0}^{2 \pi} d A \int_{\frac{\pi}{2}}^{\pi} d \theta_{1} \int_{E_{q}}^{0^{\prime \prime}} d r \cdot d H_{p s} \cos \left(\theta_{1}-90^{\circ}\right)$

The integrant in (6) is

$$
\begin{aligned}
\frac{3 k_{i}}{16 \pi}(1+ & \left.\cos ^{3} \varphi\right) S^{\prime}\left(i q \theta_{1} A r h\right) \sin \left(\theta_{1}-\frac{\pi}{2}\right) \\
& \times \cos \left(\theta_{1}-\frac{\pi}{2}\right)
\end{aligned}
$$

Hence

$$
\begin{aligned}
& H_{p s}(i q h)=\frac{3 k_{i}}{16 \pi} \int_{0}^{2 \pi} d A \int_{\frac{\pi}{2}}^{\pi} d \theta_{1}\left(1+\cos ^{2} \varphi\right) \\
& \times \sin \left(\theta_{1}-\frac{\pi}{2}\right) \cos \left(\theta_{1}-\frac{\pi}{2}\right) \int_{E_{q}}^{0 \prime \prime} d r \cdot S^{\prime}\left(i q \theta_{1} A r h\right)
\end{aligned}
$$


To the calculation of (8) we will depend on the numerical integration.

Let $T_{1}, T_{2}$ and $T_{3}$ be three points on the line section $E_{q} 0^{\prime \prime}$ which divide $E_{q} 0^{\prime \prime}$ into four equal parts and $T_{0}=E_{q}, T_{4}=0^{\prime \prime}$, and the value of $S^{\prime}\left(i q \theta_{1} A r h\right)$ at $T_{n}(n=0 \sim 4)$ be denoted by $S^{\prime}(n)$ and set for brevity

$$
\begin{aligned}
S\left(i q \theta_{1} A h\right)= & S^{\prime}(0)+4 S^{\prime}(1)+2 S^{\prime}(2) \\
& +4 S^{\prime}(3)+S^{\prime}(4)
\end{aligned}
$$

Then we can calculate as follows by Simpson's formula

$$
\int_{E_{q}}^{0 \prime \prime} S^{\prime}\left(i q \theta_{1} A r h\right) d r=\frac{1}{3} \cdot \frac{1}{4} \cdot E_{q} 0^{\prime \prime} \cdot S\left(i q \theta_{1} A h\right)
$$

For the following particular combination of $q$ and $\lambda_{i}{ }^{\prime}$, the precise calculation is indispensable to expect satisfactory result:

$$
\begin{array}{r}
q=1 \sim 30, \lambda_{1}{ }^{\prime} ; q=1 \sim 19, \lambda_{2}{ }^{\prime} ; q=1 \sim 15, \lambda_{3}{ }^{\prime} ; \\
\quad q=1 \sim 4, \quad \lambda_{4}{ }^{\prime} ; q=1 \sim 2, \lambda_{5} ; \text { for } \theta_{1}=95^{\circ}
\end{array}
$$

and

$$
\begin{aligned}
& q=1 \sim 20, \lambda_{1}{ }^{\prime} ; q=1 \sim 7, \lambda_{2}{ }^{\prime} ; q=1 \sim 7, \lambda_{3}{ }^{\prime} ; \\
& \quad \text { for } \theta_{1}=100 .
\end{aligned}
$$

For this purpose we must make three auxiliary points $T_{a}, T_{b}$ and $T_{c}$ which divide the section $T_{0} T_{1}$ into four equal parts. In this case, let us put

$f_{1}=S^{\prime}(0)+4 S^{\prime}(a)+2 S^{\prime}(b)+4 S^{\prime}(c)+S^{\prime}(1)$

$f_{2}=S^{\prime}(1)+3 S^{\prime}(2)+3 S^{\prime}(3)+S^{\prime}(4)$

where $S^{\prime}(a), S^{\prime}(b)$ and $S^{\prime}(c)$ are respectively the value of $S^{\prime}\left(i q \theta_{1} A r h\right)$ at $T_{a}, T_{b}$ and $T_{c}$. So we have only to calculate (12) instead of (9)

$$
S\left(i q \theta_{1} A h\right)=\frac{1}{4} f_{1}+\frac{9}{8} f_{2}
$$

Now put

$$
E_{q} 0^{\prime \prime} \cdot S\left(i q \theta_{1} A h\right)=C^{\prime \prime}\left(i q \theta_{1} A h\right)
$$

Substitute (13) and (10) in (8), we get

$$
\begin{aligned}
& H_{p s}(i q h)=\frac{3 k_{i}}{16 \pi} \int_{0}^{2 \pi} d A \int_{\frac{\pi}{2}}^{\pi} d \theta_{1}\left(1+\cos ^{2} \varphi\right) \\
& \quad \times \sin \left(\theta_{1}-\frac{\pi}{2}\right) \cos \left(\theta_{1}-\frac{\pi}{2}\right) \cdot \frac{1}{12} C^{\prime \prime}\left(i q \theta_{1} A h\right)
\end{aligned}
$$

Moreover let us put

$$
\left(1+\cos ^{2} \varphi\right) C^{\prime \prime}\left(i q \theta_{1} A h\right)=C^{\prime}\left(i q \theta_{1} A h\right)
$$

In the preceding calculation, $E_{q} 0^{\prime \prime}$ are expressed in the unit of the earth's radius $6370 \mathrm{~km}$. Hereafter we will use C.G.S. unit

As $1 \mathrm{~m}^{3}=10^{6} \mathrm{~cm}^{3}, 1 \mathrm{~km}=10^{5} \mathrm{~cm}$, and

$$
\begin{aligned}
& \frac{3 k_{i}}{16 \pi} \frac{1}{3} \cdot \frac{1}{4} \cdot 6370 \cdot 10^{5} \cdot 10^{-6}=3.16816 k_{i} \\
& S_{1}\left(i q \theta_{1} A h\right)=3.16816 k_{i} C^{\prime}\left(i q \theta_{1} A h\right)
\end{aligned}
$$

is the amount of primary scattered intensity received at $E_{q}$ point from a cone of one steradian with its axis in $\left(\theta_{1} A\right)$ direction and vertex at $E_{q}$. We calculated $S_{1}$ for all combinations of $i, q, \theta_{1}, A, h$.

Then we have

$$
\begin{aligned}
H_{p s}(i q h)= & \int_{0}^{2 \pi} d A \int_{\frac{\pi}{2}}^{\pi} d \theta_{1} \cdot S_{1}\left(i q \theta_{1} A h\right) \\
& \times \sin \left(\theta_{1}-\frac{\pi}{2}\right) \cos \left(\theta_{1}-\frac{\pi}{2}\right)
\end{aligned}
$$

Strictly speaking, $\Sigma\left(T_{r}\right)$ is dependent on $A$, because the mass traversed by the direct solar ray is evidently dependent on $A$, although that traversed by the scattered ray is never dependent. But when the Sun's altitude $h \geqq 30^{\circ}$ we can recognize $\Sigma\left(T_{r}\right)$ to be independent of $A$ with negligible error in this research, then $1+\cos ^{2} \varphi$ is the only one existing expression in (17) that is dependent on $A$. Let us define $F\left(i q \theta_{1} A h\right)$ by (19)

$$
\begin{aligned}
& F\left(i q \theta_{1} A h\right)=S_{1}\left(i q \theta_{1} A h\right) \\
& \times \sin \left(\theta_{1}-\frac{\pi}{2}\right) \cos \left(\theta_{1}-\frac{\pi}{2}\right)
\end{aligned}
$$

To calculate that flux of scattered radiation received by the horizontal plane we must is general use the following procedure: we will at first integrate $F$ with respect to $\theta_{1}$ and then with respect to $A$. This procedure demands us a lot of work. But we can fortunately utilize the fact that the only existing expression $\left(1+\cos ^{2} \varphi\right)$ in (19) is dependent on $A$ which is clear from the above explanation. This utilization enables us to save some extent of the labour.

As $S\left(i q \theta_{1} A h\right)$ is independent of $A$ in this 
case we can put $S\left(i q \theta_{1} h\right)$ instead of $S\left(i q \theta_{1}\right.$ $A h)$. From (17) we get

$$
\begin{aligned}
& S_{1}\left(i q \theta_{1} A h\right) \sin \left(\theta_{1}-\frac{\pi}{2}\right) \cos \left(\theta_{1}-\frac{\pi}{2}\right) \\
& =3.16816 k_{i}\left(1+\cos ^{2} \varphi\right) \cdot E_{q} 0^{\prime \prime} \cdot S\left(i q \theta_{1} h\right) \\
& \quad \times \sin \left(\theta_{1}-\frac{\pi}{2}\right) \cos \left(\theta_{1}-\frac{\pi}{2}\right)
\end{aligned}
$$

Putting

$$
E_{q} 0^{\prime \prime} \cdot S\left(i q \theta_{1} h\right)=S_{2}\left(i q \theta_{1} h\right)
$$

becomes

$$
\begin{aligned}
S_{1}\left(i q \theta_{1} A h\right) \sin \left(\theta_{1}-\frac{\pi}{2}\right) \cos \left(\theta_{1}-\frac{\pi}{2}\right) \\
=3.16816 k_{i}\left(1+\cos ^{2} \varphi\right) \sin \left(\theta_{1}-\frac{\pi}{2}\right) \\
\quad \times \cos \left(\theta_{1}-\frac{\pi}{2}\right) S_{2}\left(i q \theta_{1} h\right)
\end{aligned}
$$

Let us put

$$
\text { 3. } 16816 k_{i}\left(1+\cos ^{2} \varphi\right)=f\left(i q \theta_{1} A h\right)
$$

Then

$$
\begin{gathered}
H_{p s}(i q h)=\int_{0}^{2 \pi} d A \int_{\frac{\pi}{2}}^{\pi} d \theta_{1} \cdot F\left(i q \theta_{1} A h\right) \\
=\int_{0}^{2 \pi} d A \int_{\frac{\pi}{2}}^{\pi} d \theta_{1} \cdot f\left(i q \theta_{1} A h\right) S_{2}\left(i q \theta_{1} h\right) \\
\quad \times \sin \left(\theta_{1}-\frac{\pi}{2}\right) \cos \left(\theta_{1}-\frac{\pi}{2}\right) .
\end{gathered}
$$

It is clear that

$$
\begin{gathered}
\int_{0}^{2 \pi} f\left(i q \theta_{1} A h\right) d A=\frac{\pi}{2}\left\{f\left(i q \theta_{1} 0 h\right)+f\left(i q \theta_{1} \frac{\pi}{2} h\right)\right. \\
\left.\quad+f\left(i q \theta_{1} \pi h\right)+f\left(i q \theta_{1} \frac{3}{2} \pi h\right)\right\}
\end{gathered}
$$

Denote the blacket of the right hand side of (25) by $f^{\prime}\left(i q \theta_{1} h\right)$. Then

$$
\begin{gathered}
H_{p s}(i q h)=\frac{\pi}{2} \int_{\frac{\pi}{2}}^{\pi} d \theta_{1} \cdot f^{\prime}\left(i q \theta_{1} h\right) S_{2}\left(i q \theta_{1} h\right) \\
\times \sin \left(\theta_{1}-\frac{\pi}{2}\right) \cos \left(\theta_{1}-\frac{\pi}{2}\right)
\end{gathered}
$$

Putting

$f^{\prime \prime}\left(i q \theta_{1} h\right)=f^{\prime}\left(i q \theta_{1} h\right) \sin \left(\theta_{1}-\frac{\pi}{2}\right) \cos \left(\theta_{1}-\frac{\pi}{2}\right)$

then

$$
H_{p s}(i q h)=\frac{\pi}{2} \int_{\frac{\pi}{2}}^{\pi} d \theta_{1} \cdot f^{\prime \prime}\left(i q \theta_{1} h\right) S_{2}\left(i q \theta_{1} h\right)
$$

By putting

$$
\begin{gathered}
f^{\prime \prime}\left(i q \theta_{1} h\right) S_{2}\left(i q \theta_{1} h\right)=S_{3}\left(i q \theta_{1} h\right) \\
H_{p s}(i q h)=\frac{\pi}{2} \int_{\frac{\pi}{2}}^{\pi} d \theta_{1} \cdot S_{3}\left(i q \theta_{1} h\right)
\end{gathered}
$$

We calculated $S_{3}\left(i q \theta_{1} h\right)$ for the above mentioned values of $i, q, \theta_{1}$ and $h$. We replaced the integration of $S_{3}\left(i q \theta_{1} h\right)$ with respect to $\theta_{1}$ by two Simpson's formulae, the one is bounded by $\theta_{1}=90^{\circ} \sim 120^{\circ}$, and the other by $\theta_{1}=120^{\circ} \sim 180^{\circ}$. Hence the numerical formula of $H_{p s}$ will be

$$
\begin{aligned}
& H_{p s}(i q h)=\frac{\pi}{2}\left[\frac { \pi } { 3 } \cdot \frac { 5 } { 1 8 0 } \left[4 \left\{S_{3}\left(i q, 95^{\circ}, h\right)\right.\right.\right. \\
& \left.\quad+S_{3}\left(i q, 105^{\circ}, h\right)+S_{3}\left(i q, 115^{\circ}, h\right)\right\} \\
& \quad+2\left\{S_{3}\left(i q, 100^{\circ}, h\right)+S_{3}\left(i q, 110^{\circ}, h\right)\right\} \\
& \left.\quad+S_{3}\left(i q, 120^{\circ}, h\right)\right]+\frac{\pi}{3} \cdot \frac{30}{180}\left\{S_{3}\left(i q, 120^{\circ}, h\right)\right. \\
& \left.\left.\quad+4 S_{3}\left(i q, 150^{\circ}, h\right)\right\}\right]
\end{aligned}
$$

\section{The result of computation}

$H_{p s}$ is the flux of primary scattered radiation received by $E_{q}$ plane in each wavelength domain in (1/12) $I_{0}$ unit. Sum up these 12 values of each domain and divide by 12 , i.e. $\sum H_{p s} / 12$, then we can get the value for the total wavelength in $I_{0}$ unit which is denoted by $T$ in Table 2 . These values are given in Table 2. Multiplication of $H_{p s}$ and $I_{0}\left(\lambda_{i}{ }^{\prime}\right)$ is the flux of primary scattered radiation received by $E_{q}$ plane in $0.001 \mu$ width of wavelength with its centre at $\lambda_{i}^{\prime}$ in the unit of $\mathrm{cal} / \mathrm{cm}^{2} . \mathrm{min}$, and $\sum H_{p s} / 12$ multiplied by $I_{0}=$ 1.94 is the value for total wavelength domain in $\mathrm{cal} / \mathrm{cm}^{2} . \min$ unit.

\section{How to use Table 2}

The table shows the values of $H_{p s}$ for $h=60^{\circ}$ and is expressed in the unit of (1/12) $I_{0} 10^{-n}$ for each wavelength domain denoted by $D$ and $I_{0} 10^{-n}$ for $T$. The calculated values for $h 30^{\circ}$ and $90^{\circ}$ are not given in this paper. In Table 2, $q=0$ in the column of $q$ means the earth's surface, $q=1$ and $q$ means the level of $1 \mathrm{~km}$ height and $(q+1) / 2 \mathrm{~km}$, so that 


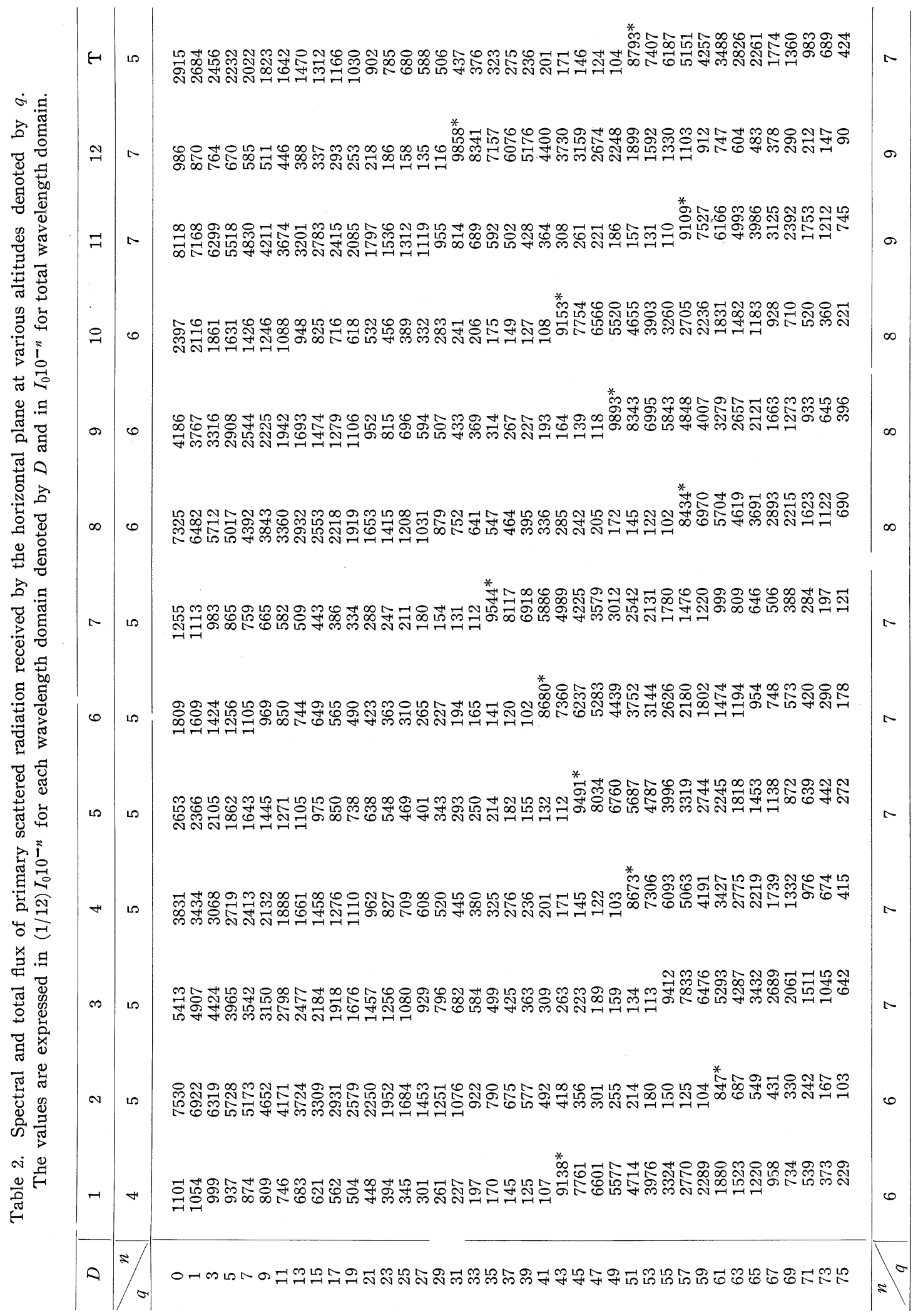


the value for the level of $500 \mathrm{~m}$ height is not calculated. The attached mark * indicates the change of common unit. Let us denote $Q$ as the value of $q$ at which the values changes a unit. It should be noticed that the value of $n$ in the array of the upper side is applied to the range from $q=0$ to $Q-1$. However, $n$ in the array of the lower side is applied to that from $Q$ to 75 .

The flux for $q=0$ has been already given

Table 3. Ratio of $H_{p s}$ for $q=0$ given in the paper (Sato 1962) to that given in this paper.

\begin{tabular}{c|ccccccccccccc}
\hline$h$ & 1 & 2 & 3 & 4 & 5 & 6 & 7 & 8 & 9 & 10 & 11 & 12 & $\mathrm{~T}$ \\
\hline 30 & 1.002 & 1.067 & 1.096 & 1.133 & 1.153 & 1.161 & 1.172 & 1.174 & 1.224 & 1.191 & 1.194 & 1.185 & 1.083 \\
60 & 1.005 & 1.050 & 1.074 & 1.099 & 1.110 & 1.124 & 1.131 & 1.145 & 1.131 & 1.142 & 1.143 & 1.147 & 1.056 \\
90 & 0.996 & 0.960 & 0.941 & 0.923 & 0.912 & 0.906 & 0.898 & 0.893 & 0.884 & 0.854 & 0.873 & 0.896 & 0.972 \\
\hline
\end{tabular}

in Table $11(\mathrm{~b})$ in the previous paper (Sato, 1962). This is slightly different from that of Table 1 in this paper. The ratio of the value in the paper (Sato, 1962) to that in Table in this paper is given in Table 2. This difference is attributed to the condition that we have only used $\theta=30,60,90$ these values being corresponding to $\theta_{1}=120^{\circ}, 150^{\circ}$ and $180^{\circ}$ in this paper, and therefore the value in the paper (Sato, 1962) is inferior to that in this paper in precision. But the value of the ratio is interesting in the meaning that it has regular change: it decreases with increasing $h$.

\section{Explanation of figure}

The result of calculation are not only expressed in Table above mentioned but also given in three figures to faciliate the synoptical understanding.

Figs. 1 to 3 give the spectral distribution of the flux of primary scattered radiation

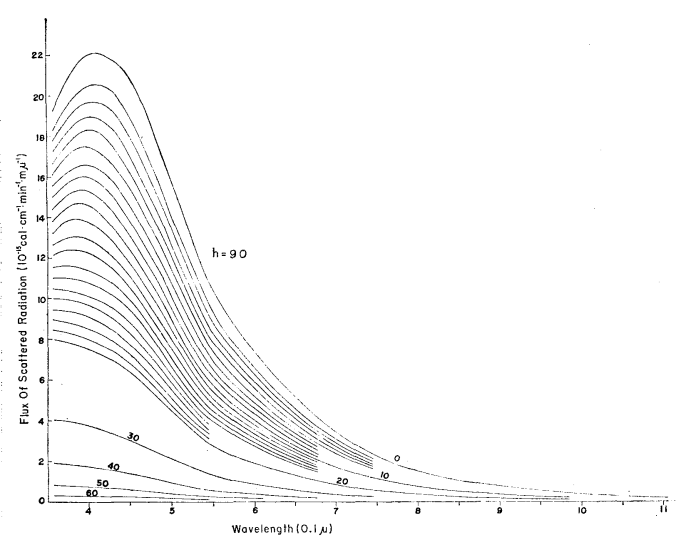

Fig. 1. Spectral distribution of the flux of primary scattered radiation received by the horizontal plane at various altitudes for solar elevation $30^{\circ}$. The numbers attached to curves denote $q$.

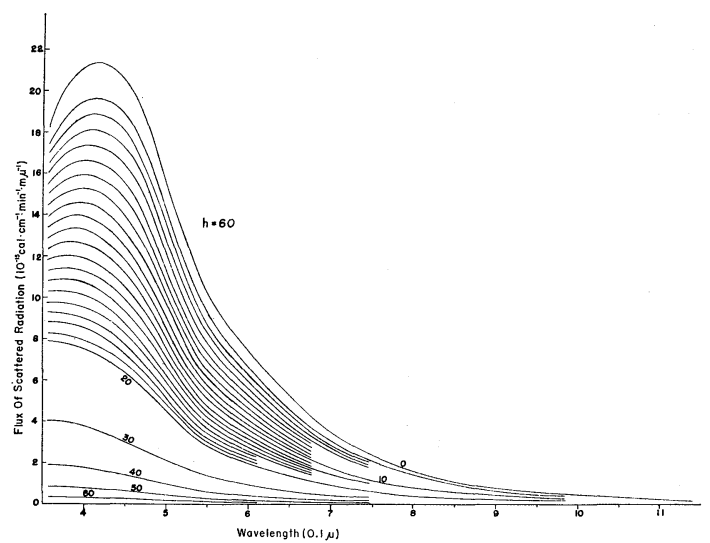

Fig. 2. Spectral distribution of the flux of primary scattered radiation received by the horizontal plane at various altitudes for solar elevation $60^{\circ}$. The numbers attached to curves denote $q$.

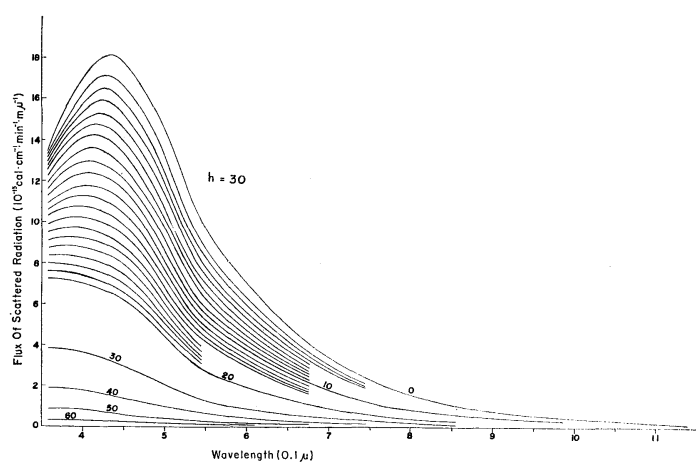

Fig. 3. Spectral distribution of the flux of primary scattered radiation received by the horizontal plane at various altitudes for solar elevation $90^{\circ}$. The numbers attached to curves denote $q$.

received by the horizontal plane for each $h$ by taking $\lambda_{i}^{\prime}$ in $0.1 \mu$ unit as abscissa and the value as ordinate in $\left(\mathrm{cal} / \mathrm{cm}^{2} . \mathrm{min}\right) 10^{-5}$ unit, the number attached to the curve being $q$. 


\section{Some results}

We can derive the following laws from the Tables and figures as far as the primary scattering is concerned;

(1) The flux decreases with increasing $q$ for each $h$ and each $\lambda_{i}^{\prime}$

(2) the flux increases with increasing $h$ for each $q$ and each $\lambda_{i}^{\prime}$

(3) the wavelength in which the flux becomes maximum decreases with increasing $q$ for each $h$

(4) the wavelength mentioned in 3 decreases with increasing $h$ for each $q$

\section{Acknowledgments}

The author expresses his sincere thanks to
Dr. M. Kano of the Meteorological Research Institute for his earnest and helpful discussions. The expense of this work was defrayed by the Special Fund for Sciences of Educational ministry of Japan.

\section{References}

Sato, T., 1955: On the scattering of the sun's ray in the high atmosphere (1). J. meteor. Soc. Japan, 33, 194-204.

- 1962: The Intensity of Scattered Light for Each Wavelength in a Rayleigh Atmosphere Composed of Spherical Shells. Ibid., 40, 148-161. , 1964: On the scattering of the sun's ray in the high atmosphere (2). Ibid., 42, 163-172.

\title{
上空における散乱光 (III)
}

\author{
佐 藤 隆夫 \\ 長崎大学
}

地上を No. 0 とし, 上空 $1 \mathrm{~km}$ を No. $1,500 \mathrm{~m}$ 上年するごと飞 No.を一つづつ増し, $38 \mathrm{~km}$ 上空を No. 75 とする。この各高さと水平面を考光, この上面に当る第一次散乱光強度を計算した結果, 次の四つの法則のあること が判明した。

1. 強度は太陽の高度飞関係なく, 各波長について高さが增すと従って減少する。

2. 強度は各高さ及び各波長飞つき, 太陽高度が增すに従い增加する。

3. 強度が極大となる波長の值は各太陽高度につき, 高さが增すと従い減少する。

4. 強度が極大となる波長の值は各高されつき，太陽高度が增すと従い減少する。 